\title{
A Life Below the Threshold? Examining Conflict Between Ethical Principles and Parental Values in Neonatal Treatment Decision Making
}

Acknowledgements. The author would like to thank D. Micah Hester for stimulating discussion of this case and the usefulness of ethical principles for limiting parental authority.

Conflicts of Interest. The author reports no conflicts of interest.

\begin{abstract}
Three common ethical principles for establishing the limits of parental authority in pediatric treatment decision making are the harm principle, the principle of best interest, and the threshold view. This paper consider how these principles apply to a case of a premature neonate with multiple significant comorbidities whose mother wanted all possible treatments, and whose health care providers wondered whether it would be ethically permissible to allow him to die comfortably despite her wishes. Whether and how these principles help to understand what was morally right for the child is questioned. The paper concludes that the principles were of some value in understanding the moral geography of the case, but that the case reveals common bioethical principles for medical decision making are problematically value-laden because they are inconsistent with the widespread moral value of medical vitalism.
\end{abstract}

Keywords. Harm Principle, Best Interests, Threshold View, Neonatal Decision Making, Values, Medical Vitalism

Thomas V. Cunningham

Assistant Professor of Medical Humanities

Assistant Professor of Internal Medicine

Clinical Ethicist (UAMS \& ACH)

Division of Medical Humanities

UAMS College of Medicine

4301 W. Markham St., \#646

Little Rock, AR 72205

Tel. 501.661.7970

Fax 501.661.7967 


\section{A Life Below the Threshold? Examining Conflict Between Ethical Principles and Parental Values in Neonatal Treatment Decision Making}

There is often a lot of talk about families in the neonatal intensive care unit (NICU). In particular, there is often a lot of talk about mommas. There is talk about good mommas and bad mommas. We talk about mommas who are "around" and mommas who "don't show up." We talk about mommas who breast feed or pump and mommas who do not. And we talk about mommas who test positive from drug use, mommas who are also sick and in the hospital, mommas who have been abused, and mommas whose children are in protective custody.

In cases where a mother does not seem to be making good medical decisions for her child, providers will often talk about changing this. They will involve ancillary support staff, such as social workers or clinical ethicists. They will have care conferences with families. In some cases, they will take the more extreme approach of arguing that the child is a victim of medical neglect because his family refuses treatment options that will help him.

In pediatrics, the latter approach has been analyzed by Douglas Diekema, among others, who argues that the right justification for overriding parental authority for medical decision making requires determining that the child will be harmed by parental decisions, which he calls the harm principle. If all of the following eight conditions are met, then a state may justifiably interfere with parental decision-making:

1. Refusal to consent to a proposed intervention places the child at significant risk of harm;

2. The harm from refusal is imminent;

3. The refused intervention has been proven necessary to prevent the harm;

4. The refused intervention has proven efficacy;

5. The risk of harm from the refused intervention is less than the risk of harm from non-intervention, and the benefits of intervention outweigh the burdens of intervention; 
6. There is no other option for preventing the harm that is less intrusive to parental authority;

7. The state intervention could be generalized to all other similar situations;

8. Most parents would agree that the state intervention was reasonable (Diekema 2004, 252).

According to Diekema, these conditions are an improvement over other ethical standards for limiting parental authority in medical decision making because they accurately capture how medical professionals already operate. Anecdotally, many providers in pediatrics seem concerned with whether parents' choices are likely to harm their patients, not with whether parents' choices are likely to do what is in a patient's best interests.

Yet, it is important to note that the harm principle has its limitations. In theory, the harm principle, and the related principle of best interest (Brock and Buchanan 1989), justify intervention to protect a child under certain circumstances. But in practice it is often unclear how to fairly determine whether potential treatments are more likely to harm a child than nontreatment. Likewise, it is difficult to establish whose interests should be balanced when considering what is in a child's "best interests" (Hester 2007). Thus, in cases where parents seem to be making poor choices for sick children, we are often left to muddle along, striving, at our best, to construct a story for ourselves that makes sense of our participation in the parents' poor choices or justifies our extraordinary intervention to curtail their authority. What follows is one such story from the field, told as a clinical ethicist tries to make sense of the frustration and anguish felt by health care providers while also making sense of a particular parent's rights.

\section{David \& Esme}

David Espanoza was born at 25 weeks' gestational age, with common complications from prematurity and very low birth weight, including chronic lung disease and a Grade III intraventricular hemorrhage. Prior to delivery, David's 14 year old mother, Esme, and 21 year 
old father, Jaime, were living with Esme's grandparents in a rural city in the central southern US. After delivery, David was transferred to a University Hospital NICU, where hospital staff soon learned of Esme and Jaime's ages. Jaime was reported for sex with a minor and was incarcerated thereafter to await court proceedings on the charge of rape. Though they too were reported for neglect and child endangerment, Esme was returned to her parents' home after discharge.

Two weeks into his hospitalization, David suffered what was diagnosed as a spontaneous intestinal perforation, but may have been necrotizing enterocolitis, which did not respond to drainage and had to be surgically repaired. Although they successfully removed much of his intestines, surgeons could not close his incision, which developed a fungal infection. With his ongoing intestinal problems, NICU physicians called a family meeting because they believed David had a small chance of surviving this hospitalization. They told Esme that if he did survive, he faced a poor quality of life and many additional health problems. She wanted everything done for him and asked when he was going to be okay. She could not wait until he could come home because she was planning a pizza party for him with games and prizes.

Following the family meeting, David was weaned off of ventilator support, received total parenteral nutrition, and developed Grades III and IV retinopathy of prematurity. He then suffered an obstructed bowel that led him to vomit stool for multiple days. Although some members of the medical team believed David's prognosis was exceedingly poor, surgeons were consulted and offered a more optimistic assessment, including the possibility of surgical repair of the obstruction, yet with the caveat that it would not affect his long term prognosis because it would not improve his short gut syndrome. Nevertheless, Esme consented to surgery. After surgery David decompensated, exhibiting respiratory distress and requiring re-intubation.

At the present moment, Esme just wants David to get better, to have him home with her. She has spoken to his bedside nurse daily and visited often. But she has not been able to stay overnight because hospital policy requires individuals under 18 years old be supervised by a 
responsible adult in the waiting room or when rooming in. Both of Esme's parents work so they cannot supervise her, and she does not know any other responsible adults.

When she has visited, Esme and her mother have met routinely with pastoral care services and developed a strong rapport with one of the NICU Chaplains. They are faithful Catholics. Every time David reaches a clinical milestone physicians said he was not likely to reach, they say it is a miracle. And they believe he will continue to make a miraculous recovery, no matter what the doctors say.

According to the NICU Chaplain, the family communicates well and "realizes the realities of the situation". However, he also thinks the family is not focusing enough on David's best interests. He believes they are concerned solely with whether David will continue to survive, rather than what quality of life he might have over time. He says this is consistent with their Catholicism but he believes their beliefs would also allow them to consider David's quality of life and the idea of redirecting care toward a comfortable death. But, he says, "they are not there yet."

Since she reported David's father to law enforcement, the primary social worker involved says the family has become so evasive when she approaches them that another social worker was temporarily appointed to advocate for them in past family meetings. She believes we are only prolonging David's inevitable death and that as he gets older his life will only become worse.

David's bedside nurse knows that Esme listens to her daily reports, but since she always interrupts or asks unrelated questions, the nurse believes Esme does not fully understand the severity of his prognosis. Although his nurse has told Esme repeatedly about the severity of his many medical problems, Esme keeps asking when David will open his eyes and recognize her, and when she can hold him and feed him. David's nurse is so overcome with sadness from caring for him that she says she will remember it for the rest of her life. One day, when changing the bandage on his open, infected abdominal incision, she literally retched, not because of disgust, but because of her profound sadness at his fate. She thinks we are not doing 
any favors for David. He will never live a good life. And if Esme cannot see that, it is because she is not looking.

David's primary physicians predict that if he survives the current hospitalization he will be dependent on TPN forever. Eventually, he will develop untreatable liver failure and die. They are frustrated and tired of talking to Esme and her mother about goals of care. Esme knows his prognosis, but she remains committed to aggressive treatment. Although they are committed to providing care consistent with Esme's wishes, they wonder how it can be good for David to sustain his health longer and longer until he is so sick he finally dies despite heroic interventions. They also wonder how it is even possible to think that what may be 'best' for this boy would be to comfort him while he dies. And, finally, they wonder whether, in the event that his condition worsens to the point that further treatment would be futile, they can overrule Esme's wishes to continue aggressive treatment.

At the time of this writing, David remains alive and his case remains open. Caring for him has become an exercise in tolerance and restraint for those who are closest to him. His life embodies the dilemmas that arise when we, as individuals and as a society, strive to balance mutually exclusive values like prioritizing sanctity of life versus quality of life.

\section{A Life Below the Threshold?}

Given what I learned about David, my initial response was to conceptualize his predicament in terms of obligations the state and hospital have for protecting him from harms. I also recognized it was important to think about his best interests. As I reflected on his case I realized that in his circumstances the harm principle and best interest frameworks come into conflict. I also discovered that the specific ethical issue that prompted my involvementwhether David's neonatologists would be justified in overriding Esme's wishes for continued aggressive treatment-is one that is poorly understood in the medical ethics literature. 
The harm principle is designed to justify state intervention in the case where, presented with treatment options, one or more parent chooses an action likely to harm a child. In David's case, some healthcare providers believe Esme's decisions are causing him prolonged harm. His bedside nurse thinks we are prolonging his life in a way that does him no favors. His primary physicians think he is doomed to have multiple complications over the course of what they predict will be a brief, unpleasant life. For these people, choosing medical interventions that further his life is to harm him, and to continue to harm him day after day, after day.

Yet, although the harm principle appears applicable to David's case, I have come to believe it is not. The harm principle is designed to evaluate whether a state is justified in intervening in a parent's decision to refuse treatment. It this circumstance, a parent consents to treatment offered that may harm her child. Thus, as I attempted to apply the harm principle to David's circumstances, I discovered that since Esme is not refusing treatment, whatever harms come from her choice are not harms that come from refusal. Consequently, the harm principle does not apply.

Having rejected the harm principle in this case, I then sought other conceptual frameworks to aid me in thinking through its moral geography. One way to conceptualize David's situation is in terms of the best interest standard (or principle), thinking strictly about David's interests alone and how they might be met by continued aggressive treatment versus redirecting to comfort care. This is to think of what is best for David in terms of an individualistic interpretation of the best interest principle (Salter 2012). So understood, whether David's interests are met by either treatment pathway initially appeared to me to hang on how poor his prognoses were on the different pathways and how certain clinicians' were of their prognostications. David's neonatologists were fairly certain that treated aggressively he would be TPN dependent because of his short gut syndrome, which may lead to life threatening complications including liver failure and sepsis (Basem et al 2012). They were also certain that if he received comfort care he would die in days or weeks. Thus, David's prognoses were either a prolonged course of medical intervention that may ultimately lead to his death or a short course 
of medical intervention that would certainly lead to his death. There was also some uncertainty regarding whether he might eventually be healthy enough with aggressive treatment to tolerate feeding and overcome his predicted TPN dependency, which would improve his outcomes but still leave him at risk for significant, long term complications (Peyret et al 2011).

As an ethicist, I recognized that the question of which of these two pathways is in David's best interests is not one I was in a position to answer. It is up to the individuals with decision-making authority to decide what is best for him, which in this case would have been his mother. While I knew that in Esme's view what was best for him was to continue living, I nevertheless wondered whether this might be incorrect. I wondered whether it would be best for David to no longer live.

To examine this possibility, I wondered about the burdens of living a life with fewer cognitive and motor abilities than children who develop normally. There is scant literature on a child with David's particular complement of comorbidities. What is known suggested to me that his prognosis was radically uncertain, a circumstance where uncertainty regarding future outcomes, evidence for prognostication, the complexity of risk information, and ignorance converge such that it is unclear how to approach ethical medical decision making (Politi et al 2007). While many children with his neurological condition do well, some experience significant neurological abnormalities (Bolisetty et al 2014). Likewise, while some children who develop short gut syndrome and related complications do poorly, others fair well. Additionally, some research suggests that health care providers are more inclined to promote allowing children like David to die than older children with comparable disease burdens (Marcello et al 2011).

Given these uncertainties, I imagined a range of possibilities for David. And no matter how reduced I imagined David's capabilities, I kept thinking to myself that even if he were to be totally dependent on Esme for care, and even if she provided rather poor care for him, and even if he was extraordinarily minimally aware of his experiences in the world, it is not clear that such a life would be worse than not living at all. Rather, it was quite possible that David might not be capable of appreciating his pain, were he to have it. It was also possible he might 
not be capable of appreciating his pleasure. It was also possible that he might develop the capacity to appreciate both his pain and pleasure. Furthermore, even if he could, and he felt pain disproportionately more often than pleasure-and even if that pleasure was both slight and the height of his life's achievements-it was not clear to me that for David, irrespective of anyone else's evaluation of his interests, to experience this was, taken altogether, worse than not living at all. Indeed, to die is to cease having interests and to be in a state where any and all interests one had before death are no longer attainable. So it was not clear to me how, for David, it could be in his best interests to be in a state where he no longer has interests. Irrespective of what it means to estimate what is in someone's best interests, presumably having interests at all is better than having no interests. While it is plausible that David's injuries would result in him having interests in only the most basic comforts, like nutrition, warmth, and lack of pain, these are nevertheless interests. If David were to die, then we would have no interests and no preferences, as he would no longer exist in the state of being alive, which is a precondition for having interests and preferences.

Thus, I realized I do not know what it means to say that from David's own subjective point of view his life is not worth living at all in an individualistic sense of the best interest standard. If it is possible to make such an assessment, then in David's case doing so seems equivalent to rational suicide, but for a patient for whom rationality is not possible, as he has not attained the ability to make rational decisions.

From this reasoning I have come to believe that for cases like David's, where decisions must be made for a neonate with an uncertain prognosis and for whom a poor prognosis is appreciable, the individualistic best interest standard is a useless fiction that should be avoided. It is not possible to say with conviction what would be literally best for David, as though his interests were separable from others' interests. This conclusion is personally unsatisfying because I also believe that if a child is so significantly injured that they will never meaningfully interact with the world, then it is morally permissible to love, support, and comfort them while they die of their injuries without heroic intervention. But, in this case I felt that appealing to a 
canonical understanding of best interests would not justify even this view, much less the view that it is morally permissible to choose comfort care for a child who has some chance of living a life with moderate to severe disability. So, I investigated other ways to justify allowing David to die.

I next considered whether a relational interpretation of best interests would alter the moral assessment of David's circumstances. On this view, David's current and future interests are not all that matters; the principle also guides us to consider the interests of his family members and others (Salter 2012). As Esme's parents both worked and David's father was likely to be incarcerated, it seemed probable she would be his primary (and perhaps sole) caretaker. As a 14 year old girl, I could imagine it was not in her interests for David to continue living. Examining this further revealed that to imagine this is to see the rest of Esme's life sadly, as a child, and eventually a woman, whose opportunities are significantly diminished as she continually meets her caretaking obligations. Not only would she no longer have the opportunity to flourish in her own childhood, but she would also sacrifice her adulthood for his life. However, one need not envision Esme's life so sadly. David might do poorly, yet serve as an inspiration for her self-improvement and exemplary motherhood. He might do poorly, yet Esme might receive ample and adequate support from community and government programs designed specifically to aid her development. Or, David might do wonderfully, reaching developmental milestones that surpass doctors' prognoses, and they might create a complex, loving, and fulfilling family.

Since these and other possibilities were open, it was not clear to me how to construct David's best interest on the relational view. Instead, the relational view added additional uncertainty and complexity as I attempted to project possible familial outcomes from the range of prognostic possibilities still open to David. So, I instead considered how Esme's beliefs and values as related to David's circumstances and whether they could serve as guides for decision making. For example, if Esme believed that because of his prognosis David's continued life would be worse for him than his death, then it would be morally permissible to accept her 
assessment, and consequently, to conclude that continued life was not in his best interests. So, on the relational view if Esme thought that because of the sort of circumstances David would experience in their family it would be worse for him to continue living, then it would be permissible to accept her assessment. But, of course, Esme did not believe this. Her view was that life is intrinsically valuable, and thus, that what was best for David was continued life, regardless of its "quality." Esme's view appeared akin to medical vitalism (Mayo and Gunderson 2002) and therefore to be inconsistent even with the concept of evaluating life for its quality.

Knowing Esme's medical vitalism, I found it difficult to reason that on a relational best interest view it would be better for David to die in comfort than to undergo continued aggressive care with an uncertain prognosis. I appreciated that Esme's beliefs might be immature, underdeveloped, or cover for concern with the social or familial consequences she would face if she allowed him to die, rather than her well-founded beliefs. But despite this, I came to conclude that on the relational view of best interest it also remained in David's best interests to continue aggressive treatment. I believed I had given Esme opportunities to be more explicit about her values up to the point of becoming problematically directive in my conversations with her and her family. At no point had she stated any other overriding concerns than that she wanted whatever medical treatment was going to continue David's life and chance of recovery, no matter how remote or negligible.

As a clinical ethicist, at this point I had a feeling that may be familiar to others: I felt a discomfort arising from my perception that I knew what was morally right in the case but that I could not justify it, and in fact, could only justify its contrary. And so I tried harder. I realized that just like the harm principle, in the case of pediatric decision making the best interest principle is really designed as a means for limiting parental authority when parents seek to refuse treatment rather than when they choose further treatment that has been offered to their child. As Kopelman (2005) has argued, the best interests principle is a negative principle: it serves to limit parents' choices rather than to guide them toward exemplary decision making. 
On this reasoning, my next step was to consider whether looking away from the best interest and harm principles would shed new light on the problem. I discovered that Wilkinson has recently given an updated argument for on old and intuitive position, which he calls the threshold view. In a nutshell, his position is that there is a group of neonates for whom life sustaining treatment is not obligatory. For this group it is morally permissible for parents or physicians to decide not to offer or to withdraw life sustaining treatments. The quality that defines membership into this group of neonates is that of being "a critically ill newborn infant [that] is predicted to have severe and irremediable impairment, such that they will not be able to take part in and realize many of the good features of life" (Wilkinson 2001, 21). What makes this view a "threshold view" is that it works by positing two thresholds. At one threshold, we are to imagine that below it a developing neonate and future child has at all times a life that is "not worth living" because the benefits of continued life do not outweigh the burdens of continued life. At another threshold, we are to imagine that above it a developing neonate and future child has at all times a life that is "worth living" because the benefits of continued life outweigh the burdens. In Wilkinson's terms, at one threshold lives have "negative net future well being" and at the other threshold they have "positive net future well being" (ibid.) On the threshold view, there is a moral middle space between these two thresholds, which is filled by children with significant injuries, and thus for whom there is significant uncertainty about whether they will ultimately have positive or negative net future well being. According to Wilkinson, it is in this space that life sustaining treatment is morally permissible but not obligatory. What Wilkinson does not state is who is vested with the authority to determine which category a neonate fits into; his account provides no practical suggestion for how it might be operationalized on the wards.

Nevertheless, Wilkinson's view appeared perfectly suited to my felt need to justify the permissibility of allowing David to die while comforting him. And in a sense, it was. Granting contentious assumptions made by Wilkinson other authors dispute (e.g. Silver and Francis 2011), it is reasonable to say that David's diagnosis and prognosis place him in the 'middle 
space'. It then follows that removing life sustaining treatment would be permissible, yet also would continuing it.

However, I recalled that the question I had been asked to weigh in on was whether David's neonatologists would be justified in removing life sustaining treatments despite Esme's choices; and, if not, if they would be able to limit the treatment options they offered to Esme in the future, if his condition worsened as they expected. On this question, Wilkinson's view was clear but ultimately unhelpful. Wilkinson argues it is impermissible to continue to treat infants who fall sufficiently below the threshold of negative net future well being, and thus, in such a case, a physician is obligated to allow a child to die while comforting and supporting him, regardless of parents' wishes:

"Treatment continuation is not permissible for infants with conditions that:

[1] Reduce future well-being, either by reducing benefits or by imposing substantial burdens on the child (or both).

AND

[2] Render it highly likely that the infant will have [a life not worth living] and be harmed by continuing treatment" (Wilkinson 2011, 27)

Through Wilkinson's account, I came to believe that David's neonatologists believed something like the threshold view, or at least that they perceived it as a moral possibility that they wanted me to evaluate. It was not that they felt it was best for David to no longer live in the sense of the term "best" as it occurs in "best interests." It was also not that they felt Esme was making choices that would cause David continual harm. Rather, the most adequate reconstruction of their concern I could come up with was that they felt David was likely to have a life not worth living, meaning that his injuries and prolonged medical intervention would cause him substantial burdens with negligible or no benefits.

However, I came to believe that although Wilkinson's analysis is an apt reconstruction of their view and of my own intuitions, it is ultimately unpersuasive in David's case. When used to understand David's circumstances, I found that the crucial problem with the threshold view is 
that it presupposed and priortized a quasi-objective means for assessing whether a life is not worth living. Even if David's diagnosis and prognosis entailed that his was a life with negative net future well being, it would have been deeply problematic to alter his treatment based on this assessment, because to do so would be to strip Esme of a primary privilege of parenthood, the privilege to determine what, under the circumstances, is right and good for her child. In effect, to adopt the threshold view would have been to override and forsake Esme's values—her commitment to medical vitalism - in order to prioritize an alternative value system, one that sees life as a qualified good, with different gradations.

I realized that there were those who did not believe Esme to be acting in good faith when making medical decisions for David. At least one member of the medical team who was not primarily involved in his care questioned whether she was the right person to make decisions because she was not adequately focusing on the gravity of his situation, and was instead focusing on activities like planning a pizza party for him. To them, it seemed that Esme was in denial, immature, and lacked the cognitive ability to adequately think through the decisions David faced. On this view, what would be best for David would be to replace Esme with another decision maker, such as a court appointed guardian or grand parent. However, in the state in which this case occurred, a woman has the legal right to make health care decisions for her child, once born, regardless of her age. In that state, a 14-year-old girl has the same legal standing with regard to parental decision making as a mother of any other age. The law does not discriminate parental decision-making authority based on age, nor on competency. Rather, it allows for contesting decision-making authority if and only if the parent has harmed (or perhaps is likely to harm) a child. Thus, while in other states granting another person with temporary power to make decisions for David may have been an option, in his actual locale, it would have required first demonstrating harm, and thus, required the sort of reasoning displayed by Diekema's harm principle rather than the best interest principle or the threshold view. As discussed above, I found this strategy unworkable. 
Personally, I find the threshold view compelling. I believe that were my family to face a choice of whether to continue aggressive treatment for our child who existed in the moral middle ground, the view would help me understand our predicament. And it would help me understand how it might be defensible to allow my baby to die in comfort despite the possibility that he could live and perhaps even live with moderate disability. However, projecting my own beliefs was not at issue in David's case. Furthermore, I have not faced the decisions Esme faces. Esme's views seem deeply inconsistent with the threshold view. Consequently, in her case while the view was helpful for conceptualizing the issues, in the end it fails to justify interventions to curtail her authority because to do so would be to unjustifiably supersede her privilege as David's mother.

In the end, consulting on David's case reminded me that values lie within our cherished ethical principles, even after they are rarified through years of analyses. A basic value underlying the threshold view is that life is a qualified good. This value also underlies at least some interpretations of the best interest standard, though it is not implicit in the harm principle. In this case, reasoning through the fit between these ethical positions and the case helped to understand what was at issue, and in the end, what was the least worst option.

I remain troubled by the case, though, because I suspect Esme has not carefully considered her values or the implications of her choices. I remain concerned that Esme has a basic disposition to value life that has not survived personal reflection and scrutiny. I believe that when facing choices of such importance as those she has faced in the NICU, one should be reflective, thoughtful, and considerate. So I remain concerned that she is not making decisions well.

Furthermore, I am troubled by the experience of muddling through clinical uncertainty, where seasoned providers expressed strong convictions that this child faced a high chance of a terribly unsatisfying, significantly disabled life, and moreover, that this was a compelling reasons to focus on his comfortable death. While I concur with the view that parents ought to be vested with the authority to determine whether to withhold treatments from children with a 
sufficient likelihood of an extremely poor prognosis, I find it troubling that in practice constructing sound argument based on meaningfully certain knowledge relating to the preceding terms, "high chance," "significantly disabled," and "extremely poor prognosis," is a challenging and fraught endeavor. Even if there are moments where these terms become clear in the muddle, I believe it is inappropriate to privilege providers' assessments of the appropriate goals of care over parents.

However, as the above discussion has revealed, I appreciate the cultural and moral pluralism of our society and of the health care environment. People are free to make poor choices, just so long as they do not present a danger to others. In this case, perhaps Esme disvalues thoughtful, careful, reflective decision making. If so, then it is not clear I must compel her to make decisions in the way that I believe she ought to. Thus, in the end, I am left to rest the issue with her choices, and in this way, the rest of the NICU team and I are left to provide the care for David that is most consistent with her wants. And I wonder, isn't this how it should be?

\section{References}

Bolisetty, S., Dhawan, A., Abdel-Latif, M., Bajuk, B., Stack, J., \& Lui, K. (2014). Intraventricular hemorrhage and neurodevelopmental outcomes in extreme preterm infants. Pediatrics, 133(1), 55-62.

Brock, D., \& Buchanan, A. (1989). Deciding for others: The ethics of surrogate decision making. Cambridge University Press.

Diekema, D. (2004). Parental refusals of medical treatment: the harm principle as threshold for state intervention. Theoretical Medicine and Bioethics, 25(4), 243-264.

Hester, D. M. (2007). Interests and neonates: there is more to the story than we explicitly acknowledge. Theoretical Medicine and Bioethics, 28(5), 357-372.

Khalil, B. A., Ba'ath, M. E., Aziz, A., Forsythe, L., Gozzini, S., Murphy, F., ... \& Morabito, A. (2012). Intestinal rehabilitation and bowel reconstructive surgery: improved outcomes in children with short bowel syndrome. Journal of Pediatric Gastroenterology and Nutrition, 54(4), 505-509.

Kopelman, L. M. (2005). Rejecting the Baby Doe rules and defending a "negative" analysis of the best interests standard. Journal of Medicine and Philosophy, 30(4), 331-352. 
Marcello, K. R., Stefano, J. L., Lampron, K., Barrington, K. J., Mackley, A. B., \& Janvier, A. (2011). The influence of family characteristics on perinatal decision making. Pediatrics, 127(4), e934e939.

Mayo, D. J., \& Gunderson, M. (2002). Vitalism revitalized: vulnerable populations, prejudice, and physician-assisted death. Hastings Center Report, 32(4),14-21.

Politi, M. C., Han, P. K., \& Col, N. F. (2007). Communicating the uncertainty of harms and benefits of medical interventions. Medical Decision Making, 27(5), 681-695.

Peyret, B., Collardeau, S., Touzet, S., Loras-Duclaux, I., Yantren, H., Michalski, M. C., ... \& Peretti, N. (2011). Prevalence of liver complications in children receiving long-term parenteral nutrition. European Journal of Clinical Nutrition, 65(6), 743-749.

Salter, E. K. (2012). Deciding for a child: a comprehensive analysis of the best interest standard. Theoretical Medicine and Bioethics, 33(3), 179-198.

Silvers, A., \& Francis, L. (2011). Cloudy crystal balls do not "gray" babies make. The American Journal of Bioethics, 11(2), 36-38.

Wilkinson, D. J. (2011). A life worth giving? The threshold for permissible withdrawal of life support from disabled newborn infants. The American Journal of Bioethics, 11(2), 20-32.

\section{Discussion Questions}

1) How should the ethicist think through the relationship between apparently competing bioethical views in particular clinical circumstances?

2) Should there be a competency evaluation for parents, guardians, surrogates, or other proxy medical decision makers?

3) Should society develop policies to limit health care in circumstances where there is an appreciable likelihood of extremely poor outcomes. 